\title{
Silica nanoparticles actively engage with mesenchymal stem cells in improving acute functional cardiac integration
}

\author{
Jasmin Popara ${ }^{\ddagger}{ }^{1}$, Lisa Accomasso ${ }^{\ddagger}{ }^{1}$, Emanuela Vitale ${ }^{1}$, Clara Gallina ${ }^{1}$, Dorotea Roggio ${ }^{1}$, \\ Ambra lannuzzi ${ }^{1}$, Stefania Raimondo ${ }^{1}$, Raffaella Rastaldo ${ }^{1}$, Gabriele Alberto ${ }^{2}$, Federico \\ Catalano $^{2}$, Gianmario Martra ${ }^{2}$, Valentina Turinetto ${ }^{1}$, Pasquale Pagliaro ${ }^{1}$ \& Claudia \\ Giachino*,1 \\ 1Department of Clinical \& Biological Sciences, University of Turin, Regione Gonzole 10, 10043 Orbassano, Turin, Italy \\ 2Department of Chemistry, Interdepartmental Centre "Nanostructured Interfaces \& Surfaces" University of Turin, Via P. Giuria 7 , \\ 10125 Turin, Italy \\ *Author for correspondence: claudia.giachino@unito.it \\ ${ }^{\ddagger}$ Authors contributed equally
}

\begin{abstract}
Aim: To assess functional effects of silica nanoparticles $\left(\mathrm{SiO}_{2}-\mathrm{NPs}\right)$ on human mesenchymal stem cell (hMSC) cardiac integration potential. Methods: $\mathrm{SiO}_{2}-\mathrm{NPs}$ were synthesized and their internalization effects on hMSCs analyzed with particular emphasis on interaction of hMSCs with the cardiac environment Results: $\mathrm{SiO}_{2}-\mathrm{NP}$ internalization affected the area and maturation level of hMSC focal adhesions, accounting for increased in vitro adhesion capacity and augmented engraftment in the myocardial tissue upon cell injection in infarcted isolated rat hearts. $\mathrm{SiO}_{2}$-NP treatment also enhanced hMSC expression of Connexin-43, favoring hMSC interaction with cocultured cardiac myoblasts in an ischemia-like environment. Conclusion: These findings provide strong evidence that $\mathrm{SiO}_{2}-\mathrm{NPs}$ actively engage in mediating biological effects, ultimately resulting in augmented hMSC acute cardiac integration potential.
\end{abstract}

First draft submitted: 4 October 2017; Accepted for publication: 20 February 2018; Published online: 8 June 2018

Keywords: cell adhesion • gap junction • heart • mesenchymal stem cell • regeneration • silica nanoparticle

Human mesenchymal stem cells (hMSCs) represent an attractive therapeutic source as they appear to have beneficial effects in regenerating injured tissues [1], including the cardiac tissue [2,3].

Although both preclinical and clinical studies suggest the therapeutic potential of hMSCs, several questions remain open. An important limitation of hMSCs is the low survival rate within the first 1-2 weeks after transplantation, due to anoikis in damaged tissues [4]. Anoikis is a programmed cell death that occurs in anchorage-dependent cells when they detach from the extracellular matrix (ECM) [5,6]. Indeed, a loss of matrix anchorage and a subsequent low propensity to adhere may cause the anoikis of the transplanted MSCs. Therefore, to enhance cell survival in the site of transplantation, one should enhance the adhesion of the transplanted MSCs to limit anoikis. This might improve the success of the MSC-based therapeutic approach. Although a number of studies aim to improve MSC survival at the site of transplantation, yet few effective solutions have been proposed to solve the problem of weak cell-ECM adhesion $[7,8]$.

In the context of stem cell transplantation, another crucial aspect is the capability of hMSCs to correctly interact with the surrounding cells in the injured tissue. In the context of myocardium regeneration, cross-talk between cardiomyocyte and hMSCs represents the key point for paracrine factors exchange: protective factors released by hMSCs and factors released by cardiomyocyte may affect the fate of cell transplantation [9]. The possibility to form functional gap junctions allows the connection of the cytoplasm of adjacent cells. This will permit various small molecules, including ions and secondary messengers, to directly pass through a regulated gate between cells and this may be a modality for MSCs to exert cytoprotective effects [10]. It has been demonstrated that hMSCs express cardiac connexins, the building block proteins of gap junctions, and can form functional gap junctions with other 
cells expressing cardiac connexins including adult cardiac myocytes [11]. Therefore, the ability to increase connexin expression in MSCs would be critical to promoting cardiac regeneration.

Nanoparticle (NP)-based stem cell imaging has emerged as an essential tool for regenerative medicine, in order to track the MSCs and document both their persistence and promotion of regenerative effects [12-14]. Up to now, however, there are only a few reports on the effects exerted on MSC functions by cellular uptake of different NP types [14,15], even though this would be of great interest for the design of high-performance NP-based imaging systems for regenerative medicine processes. We have developed a method of fluorescent staining with silica NPs $\left(\mathrm{SiO}_{2}-\mathrm{NPs}\right)$ suited to track hMSCs and validated this approach both in vitro [16,17] and ex vivo [18]. We already demonstrated that $\mathrm{SiO}_{2}$-NP uptake by hMSCs was well tolerated in the long term, did induce neither cell death nor genotoxic stress and did not alter proliferative activity and differentiation potential of hMSCs [16-18].

In order to extend the use of $\mathrm{SiO}_{2}$-NPs in cardiac regenerative medicine in vivo, it is of great interest to point out any possible stem cell responses to this nanomaterial internalization. Thus, the aim of the present work was to evaluate whether any phenotypic effects could be exerted by internalization of $\mathrm{SiO}_{2}$-NPs that might ultimately impact on hMSC regenerative potential, with particular emphasis on the interaction of hMSCs with the cardiac environment.

\section{Materials \& methods}

$\mathrm{SiO}_{2}$-NPs: production, size \& photoemission properties

Pure $\mathrm{SiO}_{2}-\mathrm{NPs}$ and red fluorescent cyanine dye-doped $\mathrm{SiO}_{2}-\mathrm{NPs}$ were prepared exploiting reverse micelles formed in a water-in-oil microemulsion, as detailed by Alberto et al. [19]. For the preparation of dye-doped nanoparticles, the aminopropyltrietoxysilane derivative of IRIS3 cyanine (by Pianeta Srl, formerly Cyanine Technologies Srl, Torino, Italy) was added to the reaction system. The absorption and photoluminescence spectra of IRIS 3 range from ca. 450 to $575 \mathrm{~nm}$ and from 500 to $700 \mathrm{~nm}$, respectively. At the end of the process cyanine molecules resulted stably entrapped in the bulk of NPs based on solvatochromism test, thus the surface chemistry of NPs was not affected by the presence of IRIS3 molecules. Obtained $\mathrm{SiO}_{2}-\mathrm{NPs}$ (both pure and dye-doped) exhibited a diameter of $50 \pm 2 \mathrm{~nm}$ and possessed elevated morphologic homogeneity. When containing cyanine molecules, they displayed bright fluorescence emission and high photostability [19,20].

\section{$\mathrm{SiO}_{2}$-NP characterization \\ Dynamic light scattering}

Dynamic light scattering measurements were performed in a 90Plus Particle Size Analyzer (Brookhaven Instruments, NY, USA) at a laser wavelength of $660 \mathrm{~nm}$ and a detection angle of 90 degrees at $293 \mathrm{~K}$. Samples were prepared by suspending for up to $1 \mathrm{~h} \mathrm{SiO}_{2}$-NPs in distilled water ( $\mathrm{pH}$ 5.5) and DMEM 1\% fetal bovine serum (FBS). In all cases the $\mathrm{SiO}_{2}$-NPs concentration just before measurements was $20 \mu \mathrm{g} / \mathrm{ml}$. Dynamic light scattering plots are reported as mass distribution. Measurements were performed in triplicates.

\section{$\zeta$-potential}

The surface potential of both bare $\mathrm{SiO}_{2}$-NPs (suspended for $1 \mathrm{~h}$ in distilled water and in DMEM) and $\mathrm{SiO}_{2}-\mathrm{NPs}$ with hard corona proteins (suspended for $1 \mathrm{~h}$ in DMEM) was evaluated by electrophoretic light scattering using a Zetasizer Nano-ZS, Malvern Instruments (Worcestershire, UK). $\mathrm{SiO}_{2}-\mathrm{NPs}$ with the protein hard corona were obtained by the FBS adsorption procedure reported in the Supplementary Materials document, with final washing in DMEM.

\section{Cell culture \& drug treatments}

hMSCs isolated from the bone marrow of healthy donors were commercially obtained from Lonza (Lonza Group Ltd, Switzerland). For all the experiments cells from passage 4 to 8 were used. Briefly, hMSCs were cultured in DMEM supplemented with $1 \%$ sodium pyruvate, $1 \%$ nonessential amino acids, $1 \%$ kanamycin, $1 \%$ L-glutamine, $0.1 \% \beta$-mercaptoethanol (complete DMEM) and 10\% FBS (standard medium) (all from Sigma-Aldrich, MO, USA) and kept in an atmosphere of $5 \% \mathrm{CO}_{2}, 95 \%$ air at $37^{\circ} \mathrm{C}$ in a humidified incubator. Cells were expanded at a seeding density of $3500 \mathrm{cell} / \mathrm{cm}^{2}$ and subcultured twice a week. Exponentially growing hMSCs were seeded at $6,500 \mathrm{cell} / \mathrm{cm}^{2} 24 \mathrm{~h}$ before the two following protocols: $\mathrm{SiO}_{2}$-NPs: cells were exposed for $16 \mathrm{~h}$ to a suspension of water dissolved $\mathrm{SiO}_{2}$-NPs $50 \mu \mathrm{g} / \mathrm{ml}$ in complete DMEM 1\% FBS; $\mathrm{SiO}_{2}$-NPs used for some in vitro experiments contained no fluorophore to avoid interference of fluorescence spectra. Control (CTR): cells were incubated for 
$16 \mathrm{~h}$ with complete DMEM $1 \%$ FBS supplemented with the same volume of sterile $\mathrm{H}_{2} \mathrm{O}$ in which $\mathrm{SiO}_{2}-\mathrm{NPs}$ were dispersed. Subsequently, samples of both conditions were washed twice with warm phosphate-buffered saline (PBS) and analyzed after the treatment (Day 0) or after 1, 4, 8 and 14 days of in vitro recovery in standard medium. H9C2 cell lines were purchased from the American Type Culture Collection and cultured in complete DMEM standard medium.

\section{Transmission electron microscopy}

High-resolution transmission electron microscopy (HR-TEM) images of $\mathrm{SiO}_{2}-\mathrm{NPs}$ in their bare form and after suspension in DMEM 1\% FBS followed by washing with distilled water were obtained with a Jeol 3010 microscope operated at $300 \mathrm{kV}$. Specimens were prepared by suspending the samples in distilled water and depositing a drop of the suspensions on $\mathrm{Cu}$ grids coated with a lacey carbon film, waiting until dryness.

For HR-TEM analysis, cells were prepared following procedures described by Raimondo et al. [21] See Supplementary for detailed explanation.

\section{Confocal microscopy}

hMSCs were seeded on 24-well ibiTreat microplate (Ibidi GmbH, Planegg, Germany) and, at the end of experiments, were processed for confocal immunofluorescence. Briefly, cells were fixed with $4 \%$ paraformaldehyde (PFA), permeabilized with $1 \%$ Triton-X-100 and blocked with $6 \%(\mathrm{w} / \mathrm{v}) \mathrm{BSA}$ and $2.5 \%(\mathrm{v} / \mathrm{v})$ normal goat serum.

For focal adhesion complex (FAC) analysis cells were stained for $2 \mathrm{~h}$ at room temperature (RT) with the primary antibody mouse anti-vinculin (Sigma-Aldrich) (1:600) and then incubated for $30 \mathrm{~min}$ at $37^{\circ} \mathrm{C}$ with the secondary antibody anti-mouse Alexa Fluor 488 (Thermo Fisher, MA, USA) (1:500). Quantification was performed evaluating at least 40 cells per sample using Image ${ }^{\circledR}{ }_{\text {[22]. }}$

For Connexin- 43 analysis, both permeabilized and nonpermeabilized cells were incubated for $16 \mathrm{~h}$ at $4^{\circ} \mathrm{C}$ with the primary antibody mouse anti-Connexin-43 (1:400) and then the secondary antibody anti-mouse Alexa Fluor 488 (1:500) was added. Nuclear staining was performed with Hoechst-33342 $(5 \mu \mathrm{g} / \mathrm{ml})$. Quantification was assessed evaluating at least 120 cells per sample using Image $J^{\circledR}$.

For LC3 analysis, permeabilized cells were incubated for $16 \mathrm{~h}$ at $4^{\circ} \mathrm{C}$ with the primary antibody rabbit anti-LC3 (1:200) and stained for 60 min at RT with the secondary antibody anti-rabbit Alexa Fluor 488 1:500 in PBS.

To mark late endosomes and lysosomes, cells were incubated for $15 \mathrm{~min}$ at $37^{\circ} \mathrm{C}$ with LysoTracker Green $(2 \mu \mathrm{mol} / \mathrm{l})$ (Life Technologies, Italy) in complete DMEM and analyzed with inverted confocal laser scanning microscope LSM 800 (Carl Zeiss, Germany).

\section{Flow cytometry}

For Connexin-43 surface expression, approximately 400,000 hMSCs were trypsinized and maintained in 10\% FBS culture medium for $2 \mathrm{~h}$ at RT, on a rocker platform to enable regeneration of the receptors. Cells were then washed with PBS, fixed 15 min at RT with 4\% PFA, washed with PBS supplemented with 1\% FBS and stained for $30 \mathrm{~min}$ at $4^{\circ} \mathrm{C}$ with rabbit polyclonal anti Connexin-43 primary antibody (Sigma-Aldrich) 1:60 in PBS, followed by incubation with secondary antibody goat anti-rabbit conjugated with phycoerythrin (PE, Southern Biotech, USA) 1:500 in PBS for $30 \mathrm{~min}$ at $4^{\circ} \mathrm{C}$. Then cells were washed once with PBS, suspended in cold PBS, acquired with CyAN ADP flow cytometer (Beckman Coulter, CA, USA) and analyzed by Summit 4.3 software. At least 20,000 events per sample were collected.

\section{Cell adhesion \& cell detachment assays}

For cell adhesion assay, cells were detached with $0.25 \%$ Trypsin- $0.2 \%$ EDTA and resuspended in DMEM with $10 \%$ FBS in a $15 \mathrm{ml}$ sterile tube to a final concentration of $1 \times 10^{5} / \mathrm{ml}$. Cells were maintained in rotation at RT for $2 \mathrm{~h}$ to allow surface receptor recovery. Then cells were spin down and resuspended at a final concentration of $2 \times 10^{5} / \mathrm{ml}$. A $100 \mu \mathrm{l}$ of cells' suspension $\left(2 \times 10^{4}\right.$ cells $)$ was then seeded in fibronectin $(10 \mu \mathrm{g} / \mathrm{ml})$ coated 96-well plates and cells were allowed to adhere for 5 or $15 \mathrm{~min}$ at $37^{\circ} \mathrm{C}$ in the $\mathrm{CO}_{2}$ chamber. At least three wells were analyzed for each condition. The assay was stopped discarding the medium carefully without scratching the bottom of wells and rinsing cells once with PBS and washing three-times with $0.5 \%$ BSA in PBS.

For cell detachment assay, cells were seeded in fibronectin $(10 \mu \mathrm{g} / \mathrm{ml})$ coated 96-well plates at a density of $10,000 / \mathrm{cm}^{2}$ and cells were allowed to adhere overnight at $37^{\circ} \mathrm{C}$ in the $\mathrm{CO}_{2}$ chamber. Cells were treated with either control medium or $\mathrm{SiO}_{2}$-NPs and then incubated with $0.025 \%$ Trypsin- $0.02 \%$ EDTA for 4 or 8 min. The assay 
was stopped discarding the detached cells carefully without scratching the bottom of wells and rinsing cells once with DMEM 10\% FBS and washing for three-times with PBS -0.5\% BSA.

For both assays, cells were then fixed with 4\% PFA for $10 \mathrm{~min}$ at RT and washed with PBS. To quantify the amount of adherent cells $0.1 \%$ crystal violet was added to each well and incubated for $10 \mathrm{~min}$ at RT; after three washes with $\mathrm{ddH}_{2} \mathrm{O}(200 \mu \mathrm{l} /$ well), the plates were let to dry up completely. Finally, $100 \mu \mathrm{l}$ of $2 \%$ SDS were added to each well and incubated for 10 min with gentle shaking at RT. Fluorescence emission (excitation filter: $485 \pm 20 \mathrm{~nm}$; emission filter: $535 \pm 25 \mathrm{~nm}$ ) was read with an Infinite F200 microplate reader (Tecan Group Ltd., Switzerland).

Cell injection in ex vivo perfused infarcted rat hearts

Perfusion of isolated rat hearts \& injection of $\mathrm{SiO}_{2}-N P_{s-h M S C s}$

Experiments were performed on adult male Wistar rats (450-550 g body-weight) $(\mathrm{n}=4)$. Animals were heparinized (2500 U im., Roche, Italy) and anaesthetized with urethane $(1 \mathrm{~g} / \mathrm{kg}$ ip.) $10 \mathrm{~min}$ later. The hearts were rapidly excised, cannulated via the aorta and retrogradely perfused with oxygenated Krebs-Henseleit buffer containing (in mmol/l) $127 \mathrm{NaCl}, 17.7 \mathrm{NaHCO}_{3}, 5.1 \mathrm{KCl}, 1.5 \mathrm{CaCl}_{2}, 1.26 \mathrm{MgCl}_{2}$ and $11 \mathrm{D}$-glucose, supplemented with $5 \mu \mathrm{g} / \mathrm{ml}$ lidocaine. A constant flow was adjusted with a proper pump (Watson-Marlow 313, UK) to obtain a typical coronary perfusion pressure of $80-85 \mathrm{mmHg}$ during initial stabilization. Thereafter, the same flow level $(9 \pm 1 \mathrm{ml} / \mathrm{min} / \mathrm{g})$ was maintained throughout the experiment. The temperature of perfusate and hearts were kept constant at $37^{\circ} \mathrm{C}$ throughout the experiments.

To produce an infarction, after 30-min stabilization, the left descending coronary artery was occluded for $30 \mathrm{~min}$ (Supplementary Figure 2, 'Ischemia', recognized by pale-colored tissue after coronary occlusion and by a fall in left ventricular developed pressure) and then re-opened to full reperfusion of the left ventricle (Supplementary Figure 2, 'Reperfusion'). Hearts were divided into two groups, one group received 5-chloromethylfluorescein diacetate (CMFDA)-treated and the other received red fluorescent cyanine dye-doped $\mathrm{SiO}_{2}$-NPs-treated hMSCs. A total of $1 \times 10^{6}$ cells were injected in the apex after $30 \mathrm{~min}$ of reperfusion. All the experiments were then stopped after total $6 \mathrm{~h}$, as this time was considered the end point for proper ex vivo experiments, according to Penna et al. [23].

Heart processing \& immunofluorescence analysis of tissue slices

At the end of perfusion, atria and vasa were discarded and ventricles were fixed $3 \mathrm{~h}$ RT with 4\% PFA with gentle stirring. After four washes with PBS, tissues were submerged in PBS supplemented with $30 \%$ sucrose, allowed to precipitate overnight at $4^{\circ} \mathrm{C}$ and then incubated $30 \mathrm{~min} \mathrm{RT}$ in a solution $1: 1$ of $30 \%$ sucrose and TissueTek ${ }^{\circledR}$ Optimal Cutting Temperature (OCT ${ }^{\mathrm{T} M}$, Sakura FineTek, CA, USA). Finally, tissues were embedded in OCT and stored at $-80^{\circ} \mathrm{C}$. Transverse slices $10 \mu \mathrm{m}$ thick were obtained starting from the apex with a CM 1900 cryostat (Leica Microsystems GmbH, Wetzlar, Germany) and processed. Sections for ultrastructural analysis were processed for immunofluorescence. Briefly, they were rinsed in PBS, permeabilized $20 \mathrm{~min}$ at RT with $0.5 \%$ Triton-X-100 and blocked $1 \mathrm{~h}$ at RT with $6 \% \mathrm{wt} / \mathrm{vol} \mathrm{BSA}$ and $2.5 \%$ NGS in PBS. The primary antibody mouse anti-sarcomeric $\alpha$-actinin 1:600 in PBS was incubated overnight $4{ }^{\circ} \mathrm{C}$ and the secondary antibody anti-mouse Alexa Fluor 488 1:1000 in PBS was incubated $1 \mathrm{~h}$ at RT. After several washes with PBS, samples were finally mounted with Mowiol and conserved at $4^{\circ} \mathrm{C}$.

\section{Dye transfer assay}

To monitor diffusion of fluorescent molecules through gap junctions (dye coupling) we used a method similar to the

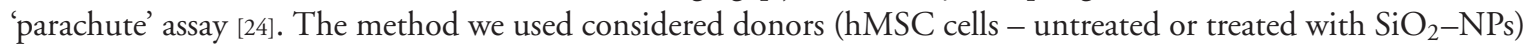
loaded with a gap junction permeant dye, in other words, Calcein-AM and unlabeled acceptors (cardiomyoblasts H9C2 cells).

For confocal microscopy analysis, hMSCs were labeled with Calcein-AM (Sigma-Aldrich) membrane permeant dye $(1 \mu \mathrm{M})$ for $30 \mathrm{~min}$ at $37^{\circ} \mathrm{C}$. After labeling, the cells were cocultivated (hMSC:H9C2 ratio 1:2) for $6 \mathrm{~h}$ at $37^{\circ} \mathrm{C}$ and then analyzed for their fluorescence. The two cell types were distinguished morphologically. Carbenoxolonedisodium (Sigma-Aldrich) was used to inhibit Calcein-AM transfer through gap junctions. Cells were preincubated with the inhibitor $(100 \mu \mathrm{M})$ overnight at $37^{\circ} \mathrm{C}$. After labeling, the cells were cocultivated (hMSC:H9C2 ratio 1:2) for $6 \mathrm{~h}$ at $37^{\circ} \mathrm{C}$ and then analyzed for their fluorescence. The two cell types were distinguished morphologically.

For flow cytometry analysis hMSCs were labeled with Calcein-AM in the same way as for confocal microscopy analysis. After labeling, hMSCs were cocultivated with $\mathrm{H} 9 \mathrm{C} 2$ for $24 \mathrm{~h}$ at $37^{\circ} \mathrm{C}$ and incubated with $21 \% \mathrm{O}_{2}$ and $5 \%$ 
$\mathrm{CO}_{2}$, in other words, normoxia or in a hypoxic chamber with $1 \% \mathrm{O}_{2}$ and $5 \% \mathrm{CO}_{2}$, in other words, hypoxia. Before starting a coculture, $\mathrm{H} 9 \mathrm{C} 2$ intended for hypoxia were maintained for $150 \mathrm{~min}$ in $0 \% \mathrm{O}_{2}, 5 \% \mathrm{CO}_{2}$, glucose-free medium to mimic ischemia as reported by Cselenyák et al. [25]. CD90 staining was performed using specific MSC marker anti CD90-PE antibody (BD Pharmingen, CA, USA) 1:10 in PBS for 30 min at $4^{\circ} \mathrm{C}$ to distinguish hMSCs and H9C2. Cells were acquired with CyAN ADP flow cytometer (Beckman Coulter) and analyzed by Summit 4.3 software. At least 100,000 events per sample were collected.

As a negative control, Vybrant ${ }^{\circledR}$-5-(and-6)-carboxyfluorescein diacetate, succinimidyl ester (CFDA SE; Molecular Probes) labeled hMSCs were used. CFDA-SE is a fluorescein-based tracer. Once inside the cell, nonspecific esterases cut its lipophilic groups and the dye remains in the cell. The concentration of $2.5 \mu \mathrm{M}$ in PBS was used for $15 \mathrm{~min}$ at $37^{\circ} \mathrm{C}$. At least 20,000 events per sample were collected.

\section{Cell metabolism}

To evaluate cell metabolism, CellTiter-Blue ${ }^{\circledR}$ (Promega, Leiden, the Netherlands) assay was used. See Supplementary Materials for more information.

\section{Western blot analyzes}

hMSCs were lysed with RIPA buffer and $12 \mu \mathrm{g}$ of protein samples was loaded. SDS-PAGE (12\% Bis-Tris gel, Invitrogen, CA, USA), Polyvinylidene difluoride transfer membrane and quantification BCA assay (Thermo Scientific, MA, USA) were used. Membranes were blocked in 5\% milk for $1 \mathrm{~h}$ at room temperature and probed with the primary antibodies (anti-LC3B, anti-p62/SQSTM1 purchased from Sigma-Aldrich) (1:1000) overnight at $4^{\circ} \mathrm{C}$, followed by secondary antibodies (1:5000) for $1 \mathrm{~h}$ at RT. Bands were visualized using an enhanced chemiluminescence kit (SuperSignal ${ }^{\text {TM }}$ West Pico PLUS, Thermo Scientific).

\section{Statistical analysis}

Data are expressed as a mean \pm standard error of the mean (SEM) of at least three different experiments or as the mean \pm standard deviation (SD) of representative experiments. Statistical comparisons were performed with either paired or unpaired Student's $t$-test. Differences with $\mathrm{p}<0.05$ were regarded as statistically significant.

\section{Results}

The state of $\mathrm{SiO}_{2}$-NPs when administered to cells and their efficient internalization by hMSCs

For the administration of NPs to cells, an aliquot of the water suspension of NPs, where they were almost monodispersed (Figure 1A), was added to complete DMEM - 1\% FBS, and this resulted in the formation of agglomerates of ca. $1 \mu \mathrm{m}$ in size, stable over at least $1 \mathrm{~h}$ (Figure 1B), in other words, a time corresponding to the incubation stage with cells inspected by HR-TEM. It is worth mentioning that a protein corona was formed on NPs agglomerates when suspended in DMEM-1\% FBS [17], that was possible to image for the very few small clusters of NPs found on the specimen grid when depositing a drop of NPs-DMEM 1\% FBS suspension (Figure 1A $\& \mathrm{~B})$. According to the formation of the protein corona, the $\zeta$-potential of NPs changed in a large extent, passing from -25 to $-9 \mathrm{mV}$ for $\mathrm{SiO}_{2}$-NPs in the bare form and in DMEM 1\% FBS, respectively (Figure $1 \mathrm{~A} \mathrm{\&} \mathrm{B}$ ). Some agglomeration of NPs was retained during incubation with cells, as indicated by HR-TEM analysis, which allowed observing invaginations of the hMSC plasma membrane that surrounded ensembles of NPs, explainable as the beginning of an endocytic process (Figure 1C).

The cytofluorimetric analysis confirmed that virtually all hMSCs possessed internalized NPs by the end of the treatment (16 h) (Supplementary Figure 1).

\section{$\mathrm{SiO}_{2}$-NP internalization modifies focal adhesion structure in hMSCs}

Adhesion is an essential process of anchorage-dependent cells involved in regulation of cell functions and indeed, in regenerative medicine, one crucial aspect concerns the capability of stem cells to interact with the surrounding environment. One of the earliest and best-characterized adhesion structures are focal adhesion complexes, in other words, large macromolecular complexes that link the actin cytoskeleton to the ECM to provide traction, and properly regulated FAC dynamics are critical for cell attachment and migration [26-28].

To identify possible effects of $\mathrm{SiO}_{2}-\mathrm{NP}$ internalization on cellular FACs, we evaluated the universal focal adhesion marker vinculin $[29,30]$ by immunofluorescence and confocal microscopy analysis. Qualitative evaluation of images strongly suggested that, following $\mathrm{SiO}_{2}-\mathrm{NP}$ internalization, FACs acquired a more elongated shape and 


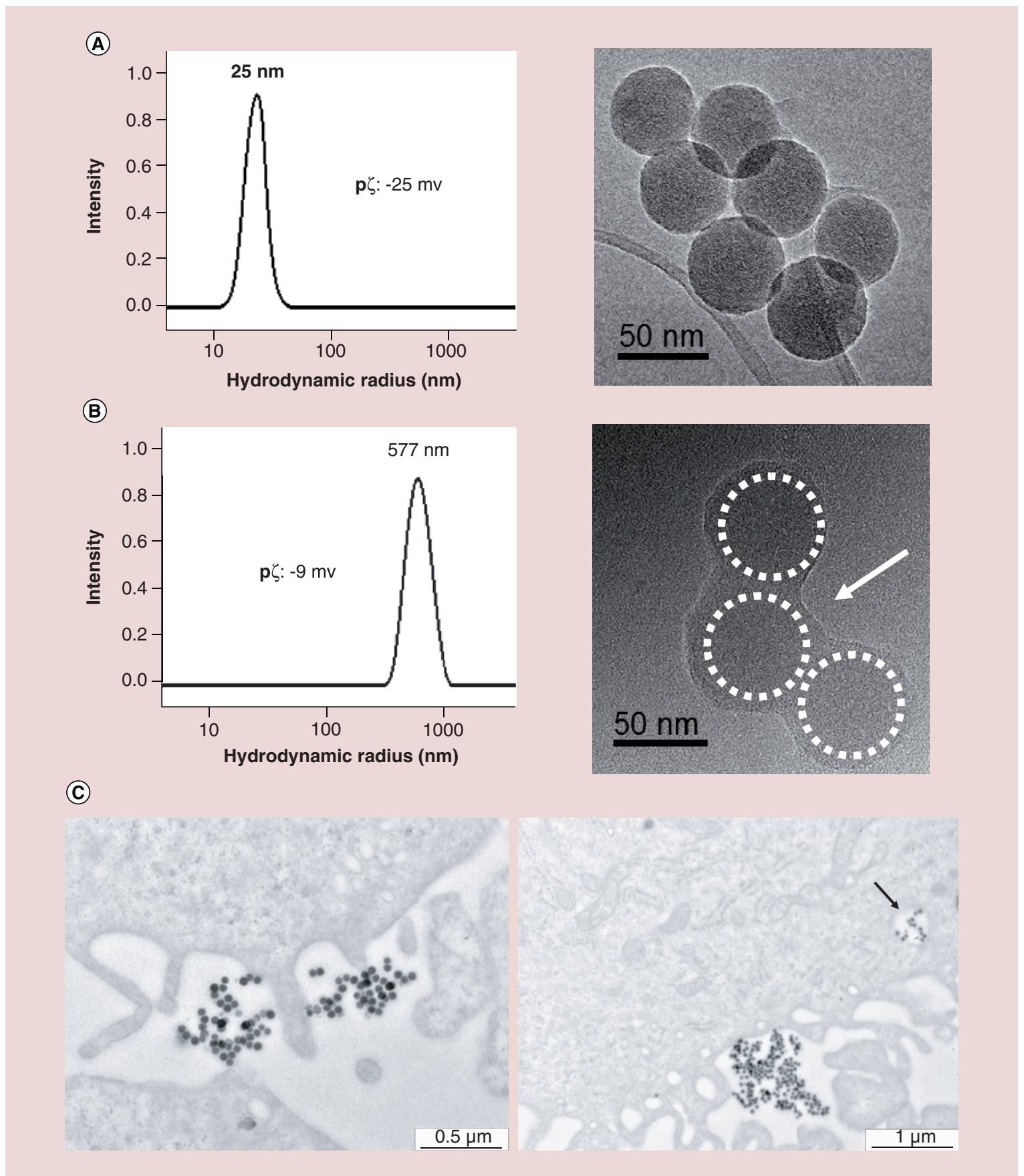

Figure 1. Silica nanoparticle characterization and interaction with human mesenchymal stem cells. (A) Hydrodynamic radius (by dynamic light scattering) and $\zeta$-potential (left panel) and TEM image (right panel) of silica-nanoparticle $\left(\mathrm{SiO}_{2}-\mathrm{NP}\right.$ ) dispersed in water. (B) Hydrodynamic radius (by dynamic light scattering) and $\zeta$-potential (left panel) and TEM image (right panel) of $\mathrm{SiO}_{2}-\mathrm{NP}$ suspended for $1 \mathrm{~h}$ in complete medium supplemented with $1 \%$ fetal bovine serum. Arrow shows the corona formed by serum protein adsorbed on the NPs. Dotted circle represents the shape of NPs. (C) TEM images of human mesenchymal stem cells after $1 \mathrm{~h}$ of incubation with $\mathrm{SiO}_{2}$-NP in complete medium supplemented with $1 \%$ fetal bovine serum. Magnification 50,000x.

TEM: Transmission electron microscopy; NP: Nanoparticle. 


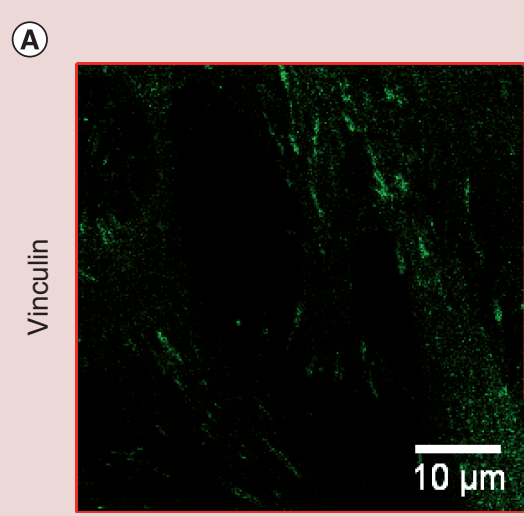

CTR

(B)

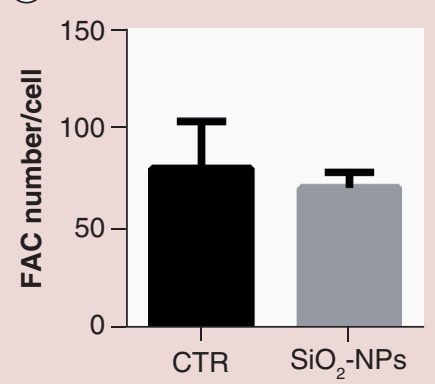

(D)

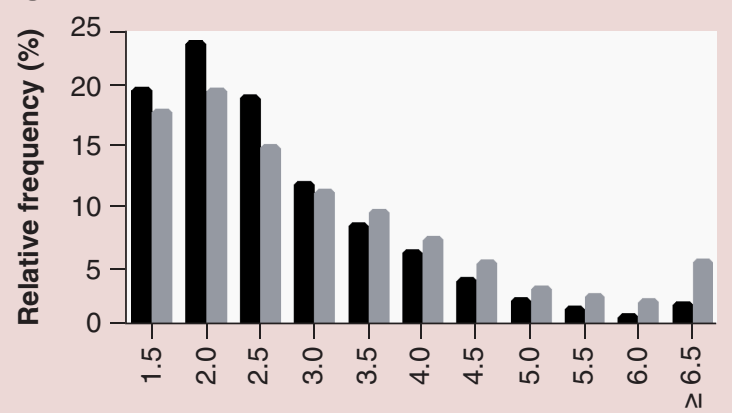

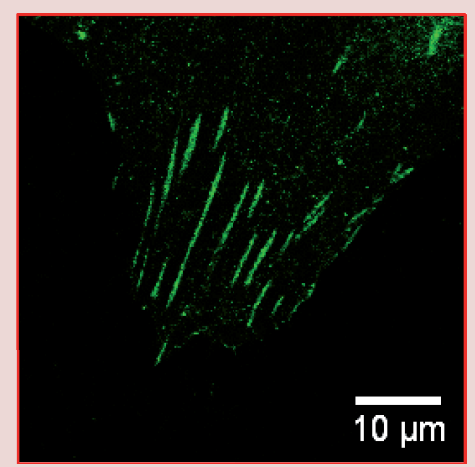

$\mathrm{SiO}_{2}-\mathrm{NPS}$

FAC length/width ratio

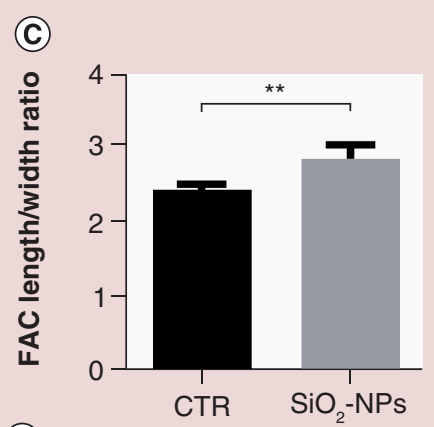

(E)

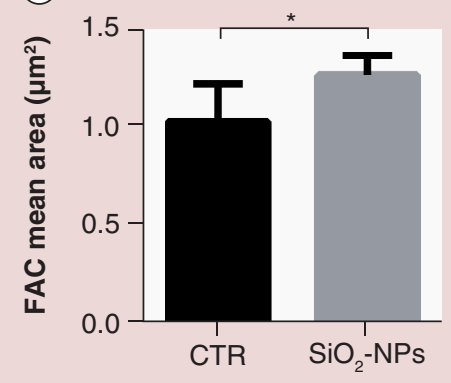

Figure 2. Silica nanoparticle effects on human mesenchymal stem cell focal adhesion complexes. Cells were treated for $16 \mathrm{~h}$ with either control medium (CTR) or silica nanoparticles $\left(\mathrm{SiO}_{2}-\mathrm{NPs}\right)$ and then stained with an anti-vinculin antibody conjugated with a green fluorophore before confocal microscopy acquisition. (A) Representative confocal images of stained cells shown the qualitative differences of the FACs. Magnification 63×. (B \& C) Quantification of the number of FACs/cell (B) and FAC mean area (C) in CTR and $\mathrm{SiO}_{2}-\mathrm{NP}$ treated human mesenchymal stem cells (hMSCS). Data are shown as mean \pm standard deviation (SD). (D) Quantification of the FAC elongation distribution (expressed as \%) in CTR and $\mathrm{SiO}_{2}$-NP treated hMSCs. FA elongation index was obtained calculating the length/width ratio of every FA. (E) Quantification of FAC elongation in CTR and $\mathrm{SiO}_{2}-\mathrm{NPs}$ treated hMSCs. Data are shown as mean $\pm \mathrm{SD}$. ${ }^{*} p<0.05 ;{ }^{* *} p<0.01$

FAC: Focal adhesion complex.

an increased size (Figure 2A). FAC analyzes showed that after $\mathrm{SiO}_{2}-\mathrm{NP}$ internalization the total number of FA remained unchanged, yet their mean size was significantly increased (Figure 2B \& C). Considering the growth model of force-induced focal adhesion driven by actomyosin-mediated tension [26,31], large focal adhesions tend to be elongated, while small focal adhesions tend to be round. FAC length and width measurements showed that in control hMSCs a low length/width ratio occurred more frequently, indicative of a prevalently round structure, while in $\mathrm{SiO}_{2}-\mathrm{NP}-\mathrm{hMSCs}$ a high length/width ratio was prevalent, indicating an elongated structure (Figure 2D $\& \mathrm{E})$. 
These data, taken together, demonstrate that $\mathrm{SiO}_{2}-\mathrm{NP}$ treatment increases hMSC FAC area and elongation, suggesting the possibility that $\mathrm{SiO}_{2}-\mathrm{NP}$ internalization induces $\mathrm{FAC}$ stabilization contributing to confer an enhanced capability of $\mathrm{SiO}_{2}-\mathrm{NP}$ treated hMSCs to adhere to a substrate [32].

\section{$\mathrm{SiO}_{2}$-NP internalization augments hMSC adhesion behavior in vitro \& ex vivo}

The adhesive strength of $\mathrm{SiO}_{2}$-NP-hMSCs was assessed using two different in vitro assays. One was the trypsin/EDTA-induced detachment assay, which measures the strength of cell attachment to fibronectin (FN)coated plates. FN was used as it is an important component of cardiac ECM and it is strongly up-regulated in vivo after myocardial infarction [33]. After treatment with trypsin/EDTA, $\mathrm{SiO}_{2}-\mathrm{NP}-\mathrm{hMSC}$ remained attached to the plate at a significantly higher level than control hMSCs after 4 and 8 min (Figure 3A).

Another technique used was the adhesion assay, which measures the adhesion of hMSCs that have been allowed to attach on FN-coated plates. Results showed an increased adhesion of $\mathrm{SiO}_{2}-\mathrm{NP}-\mathrm{hMSC}$ in comparison to control cells. After 5 and 15 min of adhesion on FN-coated plates, the presence of $\mathrm{SiO}_{2}-\mathrm{NPs}$ conferred a significantly higher ability to adhere to the substrate (Figure 3B).

We next assessed the possibility to highlight an increased adhesion behavior following $\mathrm{SiO}_{2}-\mathrm{NP}$ internalization in the challenging condition of a beating heart, subjected to ischemia/reperfusion (I/R). To this aim, an ex vivo model of perfused rat heart was used and cells were injected into the apex $30 \mathrm{~min}$ after the ligation of left descending coronary artery was removed (Supplementary Figure 2). Cells employed for these investigations were exposed for $16 \mathrm{~h}$ to $\mathrm{SiO}_{2}$-NPs and then immediately injected; as a control, we used hMSCs labeled with the CMFDA green fluorescent probe, a well-known labeling procedure commonly used to highlight cell integration in vivo and that does not interfere with hMSC adhesion properties (our data not shown). Reconstruction of a representative transverse section highlighted that $\mathrm{SiO}_{2}-\mathrm{NP}$ labeled cells were clearly visible and widespread distributed inside the walls of both right and left ventricles (Figure 3C). Differently, few CMFDA labeled cells can be detected (Figure 3D). These findings are confirmed with a higher amplification and $\alpha$-actinin immunostaining (Figure $3 \mathrm{E}$ \& F).

These results demonstrate that $\mathrm{SiO}_{2}-\mathrm{NP}$ internalization confers increased adhesion ability to hMSCs both in vitro and ex vivo.

\section{$\mathrm{SiO}_{2}$-NP internalization enhances Connexin-43 surface expression \& favors the communication between hMSCs \& cardiac myoblasts}

In the context of cardiac regenerative medicine, it is necessary that hMSCs form gap junctions with the surrounding cells, to become an effective member of the myocardium [11]. As Cx43 is the most important gap junction complex in the myocardium, we investigated whether $\mathrm{SiO}_{2}-\mathrm{NPs}$ internalization by hMSCs could affect Cx 43 expression. Surface expression of $\mathrm{Cx} 43$ was first evaluated by flow cytometry analysis. Control cells were positive for $\mathrm{Cx} 43$, presenting a homogenous, low level of fluorescence. After $\mathrm{SiO}_{2}-\mathrm{NPs}$ treatment, fluorescence relative to $\mathrm{Cx} 43$ increased significantly, indicating an increase in Cx43 surface membrane expression $(\mathrm{p}<0.001)$ (Figure 4A). These data were confirmed by confocal microscopy analysis. Qualitative observation of confocal images suggested that the dot-like expression of $\mathrm{Cx} 43$ was increased in $\mathrm{SiO}_{2}$-NPs treated hMSCs (Supplementary Figure 3). Quantification of the total area of the $\mathrm{Cx} 43$ confirmed that following $\mathrm{SiO}_{2}$-NPs internalization hMSCs significantly increased Cx43 expression (Figure 4B).

These data show that $\mathrm{SiO}_{2}-\mathrm{NP}$ treatment induces the surface expression of gap junction $\mathrm{Cx} 43$ protein, suggesting the interesting possibility that $\mathrm{SiO}_{2}$-NP-hMSCs might have an increased capability to communicate with the surrounding cells. To demonstrate this hypothesis, gap junction-mediated dye transfer assays between $\mathrm{SiO}_{2}-\mathrm{NP}-$ hMSCs and the cardiomyoblast H9C2 cell line were performed. hMSCs were labeled with the gap junction permeant dye Calcein-AM or the gap junction impermeant dye CFDA-SE and cocultured with unlabeled H9C2 cells. Transfer of Calcein-AM between hMSCs and H9C2 cells was observed in confocal microscopy (Figure 4C, upper panel) and it was blocked when a gap junction inhibitor was added, as expected (Figure 4C, lower panel). Analysis of cocultures by flow cytometry demonstrated that H9C2 cells gained Calcein-AM from hMSCs while no CFDA-SE was transferred, demonstrating that gap junction intercellular communication occurs between these cells. (Figure 4D). After $\mathrm{SiO}_{2}$-NP treatment, hMSCs increased the amount of Calcein-AM transferred to H9C2 cells, in both, normoxia and hypoxia, demonstrating the correct functionality of the enhanced surface Cx43 expression. (Figure 4E). The increment of dye exchange between CTR and $\mathrm{SiO}_{2}-\mathrm{NP}-\mathrm{hMSC}$ was statistically significant in 
(A)

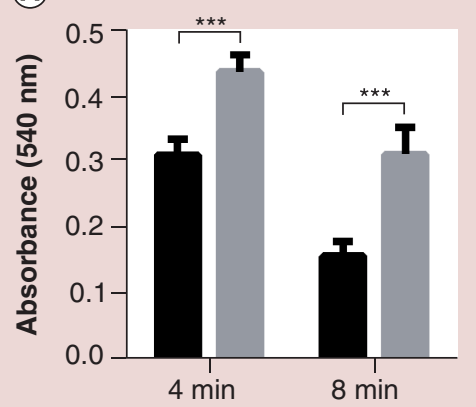

Time after detachment

(C)

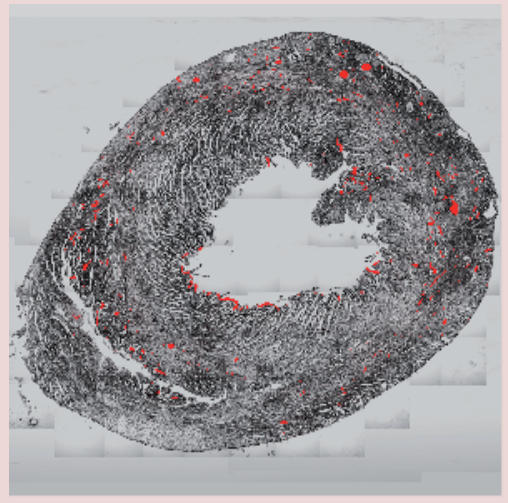

(E)

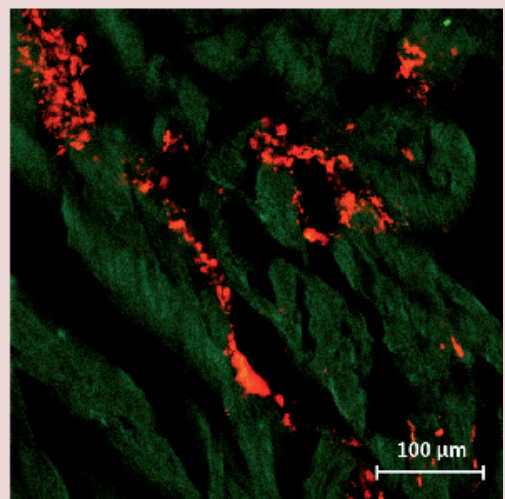

(B)

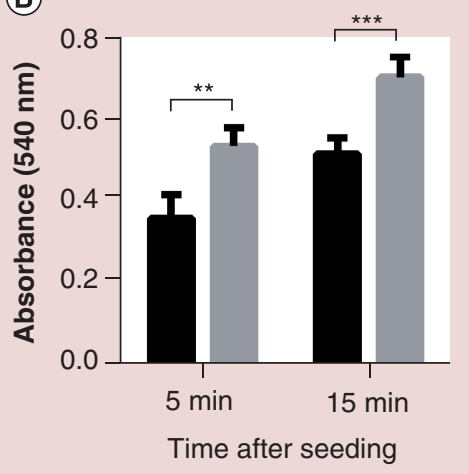

(D)

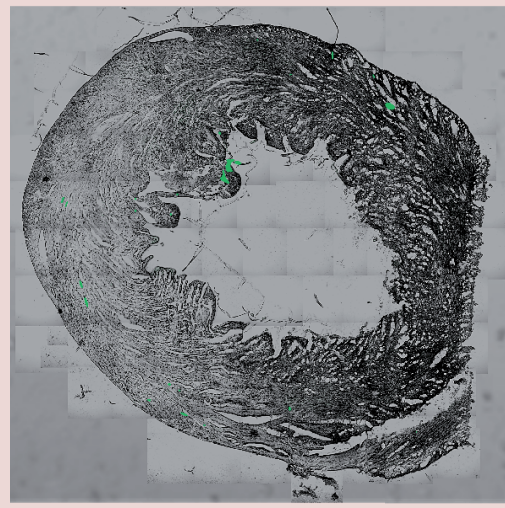

(F)

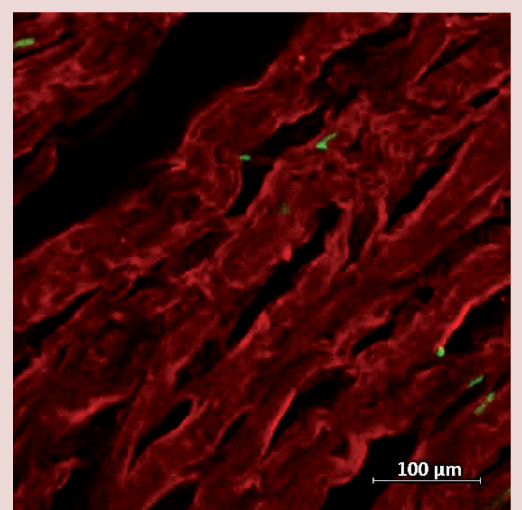

Figure 3. Silica nanoparticles effect on human mesenchymal stem cell adhesion. (A) Trypsin-based cell detachment assay. Control (CTR) and silica nanoparticle-human mesenchymal stem cells ( $\mathrm{SiO}_{2}$-NP-hMSCs) were treated with $0.025 \%$ trypsin- $0.02 \%$ EDTA for the indicated time points. The ability of hMSCs to remain attached to the substrate was evaluated. (B) Adhesion assay. CTR and $\mathrm{SiO}_{2}-\mathrm{NP}$-hMSCs were allowed to adhere on fibronectin coated plates for the indicated time points. For both assays (A \& B), adherent cells were stained with $0.1 \%$ crystal-violet and their relative absorbance was determined spectrophotometrically at $540 \mathrm{~nm}$. Data are shown as mean \pm standard deviation. (C) Imaging of CMFDA-labeled hMSCs inside infarcted hearts. (D) Imaging of red fluorescent cyanine dye-doped $\mathrm{SiO}_{2}$-NPs-labeled hMSCs inside infarcted hearts. For both images (C \& D), reconstruction of a $10 \mu \mathrm{m}$ transverse slice to show the distribution of labeled hMSCs in infarcted hearts. Green/Red points put to highlight the clusters of hMSCs. Magnification 10x, scale bar $200 \mu \mathrm{m}$. (E \& F) Superposition of sarcomeric $\alpha$-actinin staining (red in E and green in F) and labeled hMSCs (green with CMFDA in E and red with $\mathrm{SiO}_{2}-\mathrm{NPs}$ in F). Magnification $20 \times{ }^{* *} \mathrm{p}<0.01 ;{ }^{* *} \mathrm{p}<0.005$. CMFDA: 5-chloromethylfluorescein diacetate. 


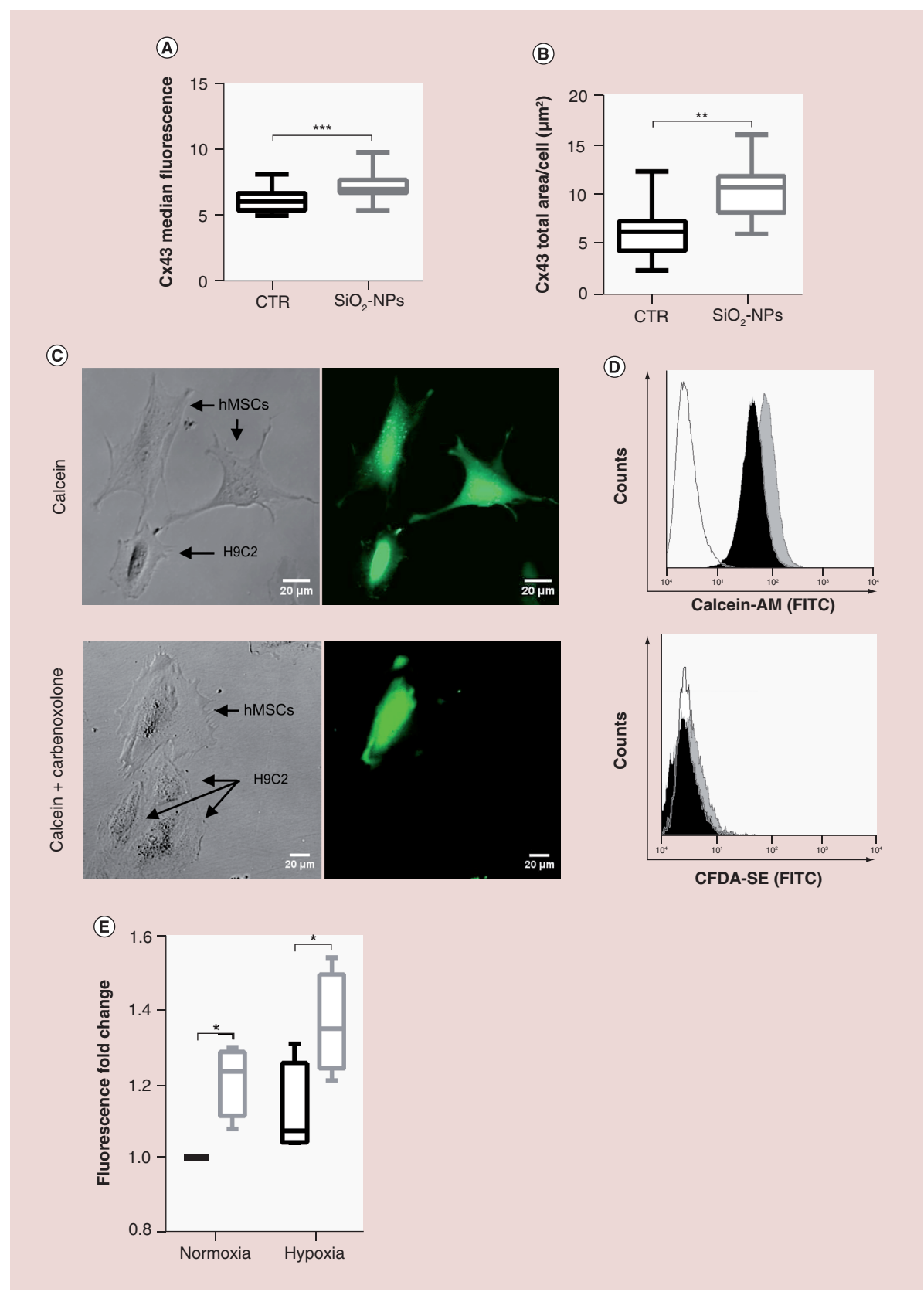

Figure 4. Silica nanoparticles effect on human mesenchymal stem cell intercellular communication. (A) Box plot showing the distribution of the median fluorescence relative to $\mathrm{Cx} 43$ in control (CTR) and silica nanoparticles $\left(\mathrm{SiO}_{2}\right.$-NPs) treated human mesenchymal stem cells (hMSCs) (eight independent experiments) obtained by flow cytometry. Paired $t$-test were performed $* * * p<0.001$. (B) Box plot showing the quantification of Cx43 area in CTR and $\mathrm{SiO}_{2}-\mathrm{NPs}$ treated hMSCs obtained by confocal microscopy. At least 120 cells were analyzed. Unpaired $t$-test was performed. ${ }^{* * *} p<0.0001$. One representative experiment out of three. (C) Representative dye transfer image in confocal microscopy. hMSCs were labeled with Calcein-AM (green cells) without (top panel) or in presence (lower panel) of the gap junction inhibitor Carbenoxolone and $\mathrm{H} 9 \mathrm{C} 2$ were discriminated morphologically by phase contrast images. Cells were cocultured for $24 \mathrm{~h}$ and the presence of $\mathrm{H} 9 \mathrm{C} 2$ cells that received Calcein-AM through intercellular communication with hMSCs were detected as green color in $\mathrm{H} 9 \mathrm{C} 2$ cells. (D) Representative dye transfer experiment in flow cytometry. Upper panel: $\mathrm{H} 9 \mathrm{C} 2$ cells were cultured for $24 \mathrm{~h}$ alone (white histogram) or in the presence of either CTR (light gray histogram) or $\mathrm{SiO}_{2}$-NP treated hMSCs (black histogram) labeled for $24 \mathrm{~h}$ with Calcein-AM (gap junction permeant dye). The green fluorescence detected in $\mathrm{H} 9 \mathrm{C} 2$ cells was due to the Calcein-AM they received through intercellular communication with hMSCs. Lower panel: $\mathrm{H} 9 \mathrm{C} 2$ cells were cultured for $24 \mathrm{~h}$ alone (white histogram) or in the presence of either CTR (light gray histogram) or $\mathrm{SiO}_{2}-\mathrm{NPs}$ treated hMSCs (black histogram) labeled for $24 \mathrm{~h}$ with CFDA-SE (gap junction impermeant dye). The absence of $\mathrm{H} 9 \mathrm{C2}$ cells that received CFDA-SE was verified. $\mathrm{H} 9 \mathrm{C2}$ and hMSCs were distinguished through CD90 hMSC specific surface marker. (E) Box plot showing the distribution of the mean fluorescence relative to Calcein-AM that $\mathrm{H} 9 \mathrm{C} 2$ received from CTR (black borders) and $\mathrm{SiO}_{2}-\mathrm{NPs}$ treated hMSCs (gray borders) obtained by flow cytometry. At least 80,000 cells were analyzed for each experiment. Data were normalized on control cells in normoxia. T-test was performed. * $p<0.05$. 
both, normoxic and hypoxic conditions. It was also evident that more dye was exchanged in hypoxia than in normoxia, although not in a statistically significant way. (Figure 4E).

\section{Transient lysosomal degradation impairment induced by $\mathrm{SiO}_{2}-\mathrm{NP}$ uptake could explain the} observed functional effects on hMSCs

In order to find a possible explanation for the observed functional effects, we focused our attention on the mechanism of intracellular accumulation of $\mathrm{SiO}_{2}$-NPs. Internalized $\mathrm{SiO}_{2}$-NPs displayed a punctuate distribution with some enrichment in the perinuclear area, suggestive of their accumulation within intracellular organelles. We previously demonstrated that while no colocalization of internalized $\mathrm{SiO}_{2}-\mathrm{NPs}$ with the Golgi complex, mitochondria or the endoplasmic reticulum was detected, the accumulation of $\mathrm{SiO}_{2}$-NPs in late endosomes/lysosomes was clearly observed in living cells incubated with LysoTracker Green, an organic heterotricyclic 4-bora-3a,4a-diaza-s-indacene compound that accumulates within the acidic lumen of late endosomes/lysosomes [16,18]. In accordance with our previously published results, LysoTracker staining of living cells highlighted that untreated hMSCs prevalently displayed few and small lysosomes around nuclei, while hMSCs exposed to $\mathrm{SiO}_{2}-\mathrm{NPs}$ presented a greater number of larger organelles, most of which were perinuclear (Figure 5A - day 0). A time course analysis of LysoTracker experiments on $\mathrm{SiO}_{2}$-NP-treated hMSCs highlighted that at 1 and, to a lesser extent, 4 days after the treatment larger organelles were still observed (Figure 5A - days 1 and 4). However, after 8 days of culture hMSCs displayed a normalized lysosome compartment, demonstrating that lysosomal compartment perturbation is a transient event induced by NP accumulation that can be spontaneously recovered by hMSCs (Figure 5A - day 8). Accordingly, no metabolic impairment was observed in $\mathrm{SiO}_{2}-\mathrm{NP}$ treated hMSCs up to 8 days, as evaluated through a fluorometric assay (Figure 5B). We next investigated whether the phenotypic changes observed in $\mathrm{SiO}_{2}-\mathrm{NP}$ treated hMSCs are maintained over time or are transient, analogously to lysosomal accumulation. Interestingly, we found that both increased cell adhesion and Cx43 expression returned to baseline levels in parallel with lysosomal compartment normalization (Figure 5C \& D). Further, we found that inhibition of lysosomal degradation activity, obtained using $100 \mathrm{nM}$ bafilomycin A1 for $2 \mathrm{~h}$, reproduced in CTR hMSCs both, increased adhesion and Cx43 expression observed in $\mathrm{SiO}_{2}$-NP-treated cells (Figure 6A \& B). This suggested that $\mathrm{SiO}_{2}$-NP-filled lysosomes might be transiently impaired in their degradation activity.

Considering that bafilomycin A1, a widely used inhibitor of autophagosome-lysosome fusion in vitro to determine the activity of autophagic flux, reproduced the phenotype of $\mathrm{SiO}_{2}-\mathrm{NP}$ treated cells, we addressed the hypothesis that altered lysosomal degradation might result from impaired cargo delivery to $\mathrm{SiO}_{2}$-NP-filled lysosomes from upstream donor compartments, such as autophagosomes. If this were the case, one would expect that autophagosomal components, like LC3-II and p62, being substrates for lysosomal proteolysis, accumulate in $\mathrm{SiO}_{2}$ $\mathrm{NP}$ treated cells and they do so in compartments (autophagosomes) lacking $\mathrm{SiO}_{2}-\mathrm{NPs}$ (accumulated in lysosomes), due to impaired autophagosome-lysosome fusion. In accordance with this hypothesis, WB analysis indicated a transient cellular accumulation of both LC3-II and p62 proteins in $\mathrm{SiO}_{2}-\mathrm{NP}$ treated cells that peaked at 1 day and began to attenuate at 4 days (Figure 6C). Further, confocal imaging revealed that starvation of control cells resulted in increased levels of LC3 due to the accumulation of LC3-positive autophagosomes, and this phenotype was exacerbated by concomitant application of bafilomycin to prevent lysosomal turnover of autophagosomes (Figure 6D, upper panel); cells treated with $\mathrm{SiO}_{2}-\mathrm{NPs}$, instead, displayed high levels of LC3 and accumulated LC3-positive autophagosomes largely irrespective of whether cells had been starved and/or treated with bafilomycin (Figure 6D, lower panel). Finally, a near complete lack of colocalization between $\mathrm{LC}_{3}$ and $\mathrm{SiO}_{2}$-NP-filled lysosomes (e.g., positive for LysoTracker) was revealed (Figure 6E). Altogether, these data strongly indicated an NP-induced transient impairment of autophagic flux as a likely mechanistic explanation.

\section{Discussion}

While NP-based stem cell imaging is an essential tool for regenerative medicine, cellular uptake of NPs might trigger numerous intracellular signaling events through which cells control their function and state. The central aim of this work was to evaluate any possible functional effects of $\mathrm{SiO}_{2}-\mathrm{NPs}$ on hMSC therapeutic potential, with particular emphasis on cardiac regeneration and interaction with the cardiac environment. The data collected here suggest that $\mathrm{SiO}_{2}-\mathrm{NP}$ internalization does have an influence on hMSC cell behavior, providing strong evidence that nanostructures not only passively interact with cells but also actively engage and mediate the molecular processes that are essential for regulating cell functions. 


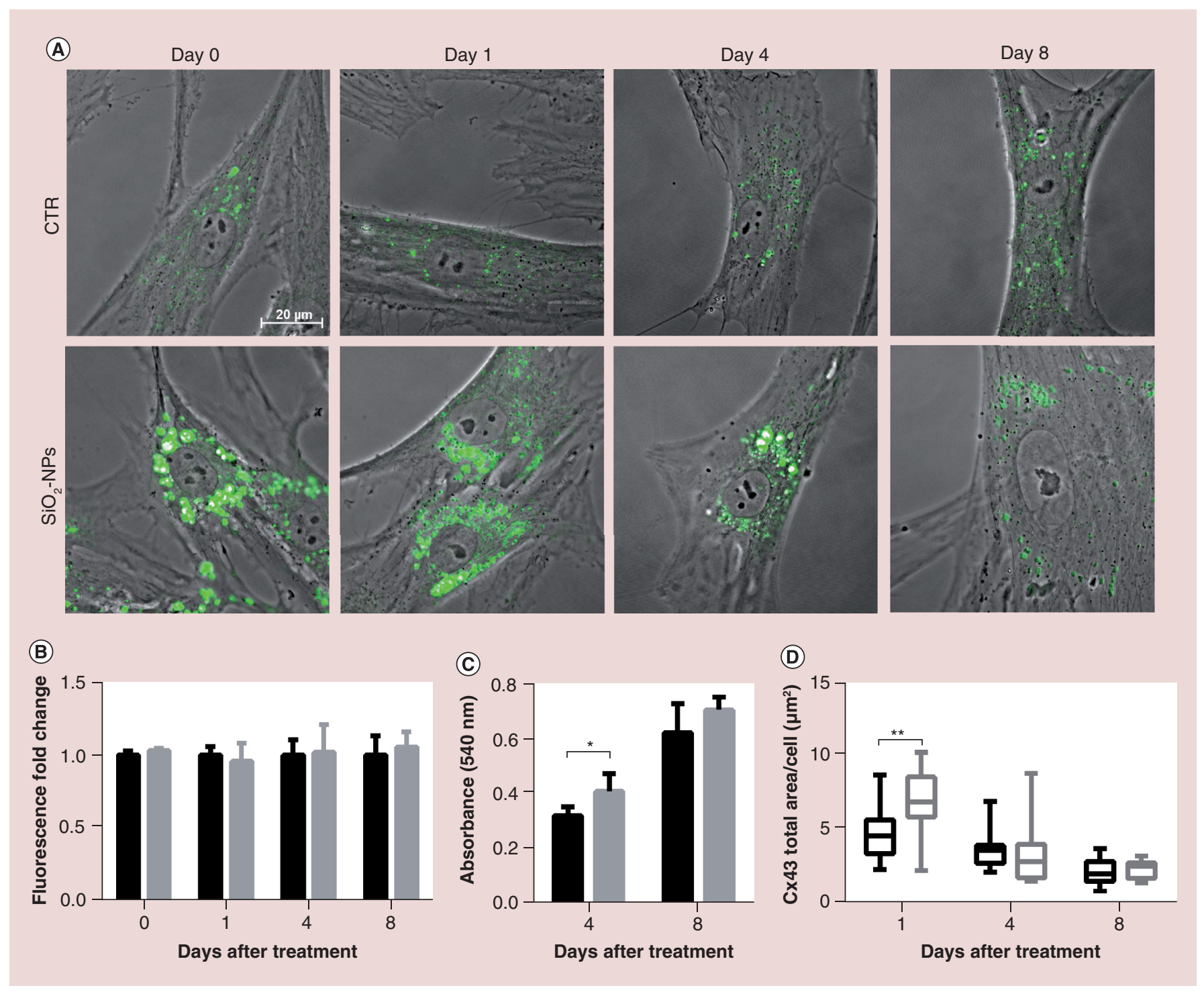

Figure 5. Time course, metabolism and phenotype analysis of silica nanoparticles effects on human mesenchymal stem cells. (A) Control (CTR) and silica nanoparticles ( $\mathrm{SiO}_{2}-\mathrm{NP}$ ) treated human mesenchymal stem cells (hMSCs) were labeled with LysoTracker (green) at day 0 - day 1 - day 4 - day 8 time points and representative images were acquired by confocal microscopy. Magnification $63 \times$. (B) CellTiter-Blue fluorescence were analyzed at day 0 - day 1 - day 4 - day 8 and the fluorescence values were normalized on control cells and represented as mean \pm standard deviation (SD). (C) CTR and $\mathrm{SiO}_{2}-\mathrm{NP}$ treated $\mathrm{hMSC}$ were allowed to recover in complete medium for 4,8 and 14 days and then adhesion assay was performed after 5 min of adhesion. Adherent cells were stained with $0.1 \%$ crystal-violet and their relative absorbance was determined spectrophotometrically at $540 \mathrm{~nm}$. Data are shown as mean \pm SD; ${ }^{*} p<0.05$. (D) CTR and $\mathrm{SiO}_{2}-\mathrm{NP}$ treated hMSCs were allowed to recover in complete medium for 1,4 and 8 days and then $\mathrm{Cx} 43$ expression was evaluated by confocal microscopy. Box plot showing the quantification of $\mathrm{Cx} 43$ area in CTR and $\mathrm{SiO}_{2}-\mathrm{NPs}$ treated hMSCs. At least 120 cells were analyzed. Unpaired $t$-test was performed. $* * p<0.01$.

First, we found that $\mathrm{SiO}_{2}-\mathrm{NP}$ treatment is associated with significant changes in focal adhesion structures. In particular, the FACs of $\mathrm{SiO}_{2}-\mathrm{NP}$ treated hMSCs are increased in mean area and elongation index as evidenced by vinculin staining. This biological effect seems not to be peculiar of $\mathrm{SiO}_{2}-\mathrm{NPs}$, however, as interestingly, Tay and collaborators obtained similar results by examining vinculin surface expression in TR146 oral mucosa cells treated with $\mathrm{SiO}_{2}, \mathrm{TiO}_{2}$ and hydroxyapatite NPs [34]. The higher occurrence of long mature FACs near cell-cell boundaries was detected through vinculin immunofluorescence analysis, suggesting the promotion of an increased adhesive phenotype [34]. In this work, we describe this phenotype for the first time in hMSCs. 
(A)

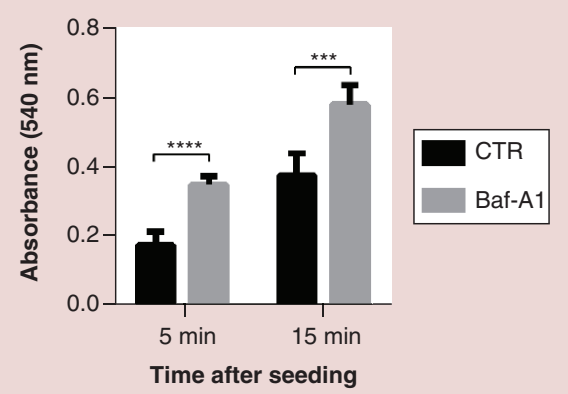

(B)

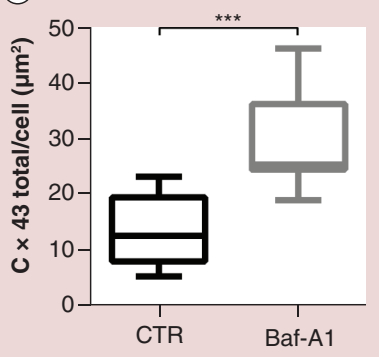

(C)

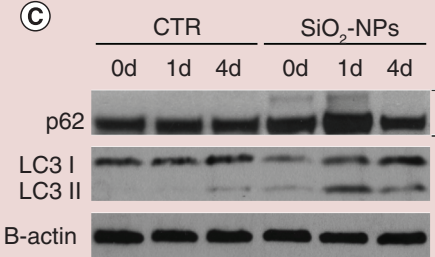

(D)
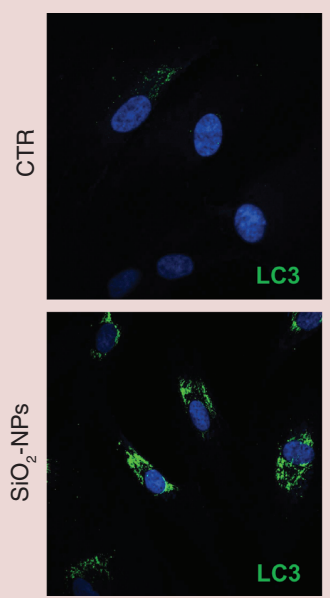

Starvation

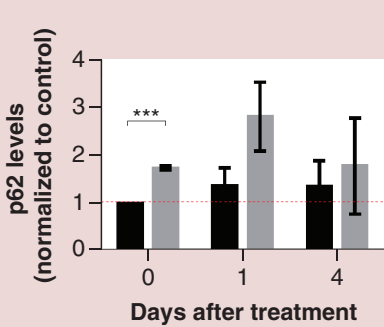

Days after treatment

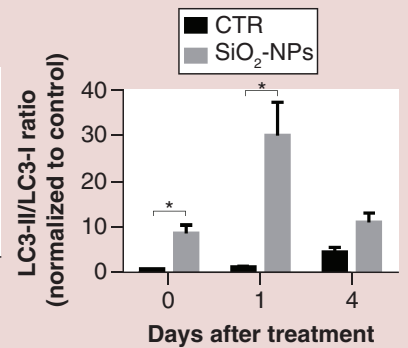

(E)
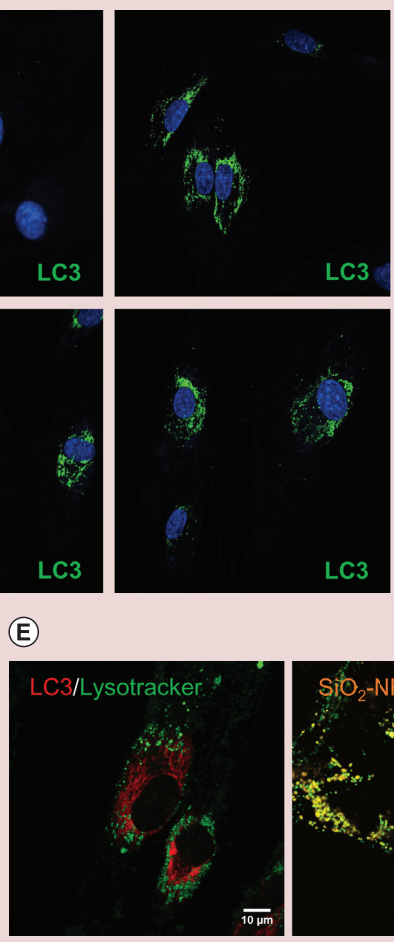

Starvation +
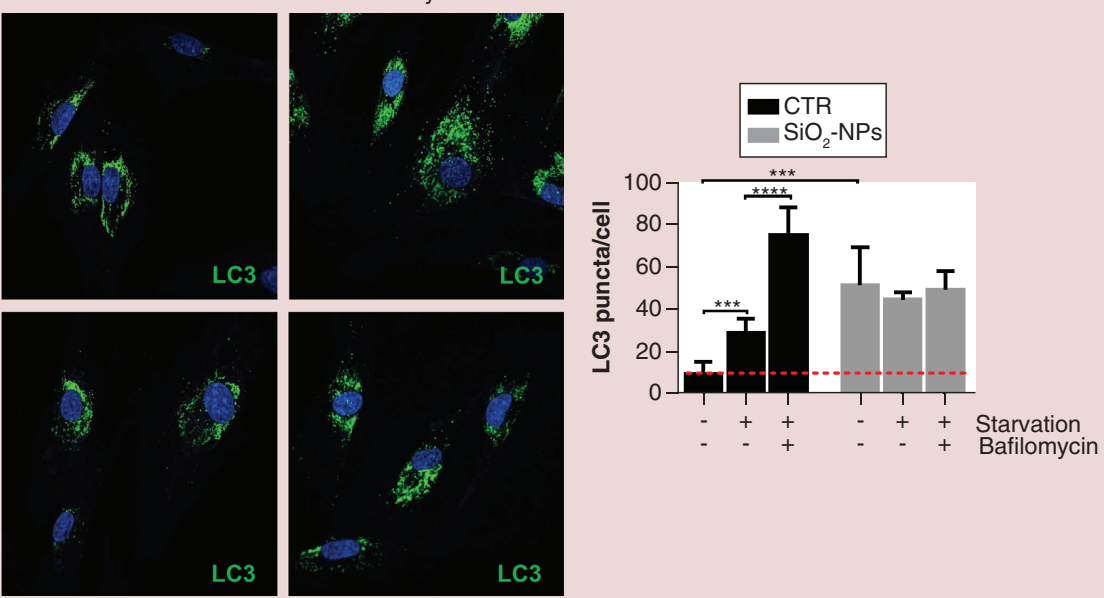

Colocalization with
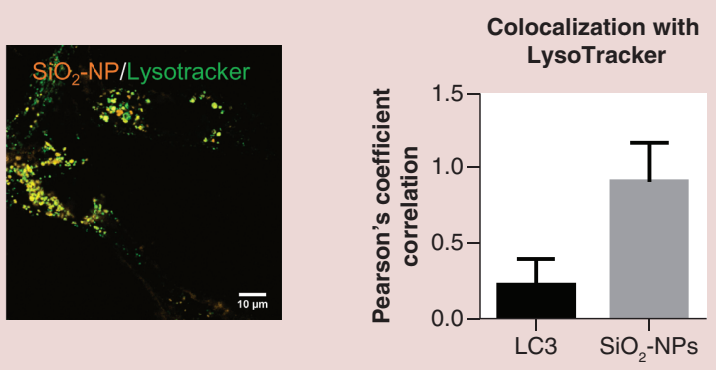

Figure 6. Inhibition of lysosomal degradation activity. (A) Adhesion assay. Human mesenchymal stem cells (hMSCs) were treated for $2 \mathrm{~h}$ with either control medium or Bafilomycin A1 $100 \mathrm{nM}$. Cells were allowed to adhere on fibronectin coated plates for the indicated time points. Adherent cells were stained with $0.1 \%$ crystal-violet and their relative absorbance was determined spectrophotometrically at $540 \mathrm{~nm}$. Data are shown as mean \pm standard deviation (SD); $* * * p<0.001, * * * * p<0.0001$. (B) hMSCs were treated for 2 h with either control medium or Bafilomycin A1 $100 \mathrm{nM}$ and then Cx43 expression was evaluated by confocal microscopy. Unpaired $t$-test was performed. Data are shown as mean $\pm \mathrm{SD} ; * * * \mathrm{p}<0.001$. (C) Control (CTR) and silica nanoparticle $\left(\mathrm{SiO}_{2}-\mathrm{NP}\right)$ treated hMSCs were analyzed by western blotting for p62 and LC3. The level of p62 and the LC3-II/LC3-I ratio were quantified and normalized to untreated control cells. Data are shown as mean $\pm S D_{i}{ }^{*} p<0.05, * * * p<0.001$. (D) Left, representative confocal images of $\mathrm{CTR}^{*}$ or $\mathrm{SiO}_{2}-\mathrm{NP}$ treated hMSCs incubated in conditions as above. After fixation, cells were stained for LC3. Right, quantification of LC3 puncta per cell. Data are shown as mean $\pm \mathrm{SD} ; * * * \mathrm{p}<0.001, * * * * \mathrm{p}<0.0001$. (E) Left, representative confocal images of $\mathrm{SiO}_{2}-\mathrm{NP}$ treated hMSCs stained with LC3 and/or LysoTracker green. Right, Pearson's correlation analyzes showing near complete lack of colocalization between LC3 and LysoTracker $(0.223 \pm 0.172)$, and strong colocalization between $\mathrm{SiO}_{2}-\mathrm{NPs}$ and LysoTracker $(0.909 \pm 0.255)$. Data are the mean $\pm \mathrm{SEM}, \mathrm{n}=3$ independent experiments. 
These findings made it plausible to hypothesize an increased adhesion capability of hMSCs due to $\mathrm{SiO}_{2}-\mathrm{NP}$ treatment, which was confirmed using in vitro and ex vivo models. While an increased in vitro cell adhesion was previously described in MSCs treated with other NP types (metal oxide NPs), we here document for the first time an augmented engraftment of $\mathrm{SiO}_{2}$-NP treated hMSCs in the myocardial tissue upon injection in infarcted isolated rat hearts. Considering that adhesion of the transplanted hMSCs is necessary not only for cell engraftment and generation of new tissue but also for a cross-talk between transplanted cells and receiving an organ, our data suggest the possibility that the internalization of a $\mathrm{SiO}_{2}-\mathrm{NP}$ stimulates a cell function (engraftment) that is required for an effective regenerative therapy. Using non-NP-based, ex vivo genetic modification approaches, several studies demonstrated that an increased adhesion phenotype of MSCs represents a crucial aspect to enhance cell survival and therapeutic potency upon transplantation to sites of injury [35,36]. MSCs derived from transgenic rats overexpressing tissue transglutaminase, a coreceptor for FN implicated in cell adhesion associated with integrins [37], displayed enhanced cell attachment and spreading features. In these cells, the formation of FACs and the increased phosphorylation of the focal adhesion-related kinases PI3K and Src were observed. Moreover, the implantation of tissue transglutaminase-transfected MSCs in rat infarcted myocardium improved cardiac functions [38]. Other studies demonstrated that an increased adhesion phenotype enhances cell survival and prevents anoikis [38-40]. In particular, MSC transfection with an integrin-linked kinase, a Ser/Thr kinase that interacts with the cytoplasmic domain of $\beta 1$ integrin, plays a crucial role in ECM assembly, cell spreading, integrin-mediated cell adhesion, signaling and survival [41].

Further, we showed that $\mathrm{SiO}_{2}$-NP treatment increases $\mathrm{Cx} 43$ surface expression in hMSCs and dye transfer experiments demonstrated the functionality of these gap junctions and the possibility to increase intercellular communication with cardiomyoblasts. Increased Cx43 expression suggests that hMSCs might readily integrate into electrical syncytia of cardiac tissue, promoting repair or serving as the substrate for a therapeutic delivery system. After acute myocardial infarction, severe loss of healthy myocardium impairs intercellular communications in the peri-infarct area and induces cardiac conduction disturbances [42,43]. Administration of naive MSCs at this phase may pose arrhythmic risks [44,45]. Previous studies addressed that abnormal cardiac conduction and arrhythmogenic remodeling after MI could be worsened by low Cx43 expression of naive MSCs [45,46]. Besides the use of NPs, growth factor (FGF-2, IGF-1, BMP-2) treatment of MSCs has been reported to augment intercellular connections with host cardiomyocytes via Cx40- and Cx43-mediated junctions [47]. Another study demonstrated that Ang II pre-treatment enhanced MSC gap junction protein expression in vitro [10]. Interestingly, injection of genetically modified MSCs that overexpressed Cx43 conferred a better reparative effect of the postinfarcted myocardium [46-48]. Previous studies also showed that overexpression of $\mathrm{Cx} 43$ in MSCs can greatly improve the therapeutic efficacy of the cell therapy in MI regardless of the cellular arrangement of Cx43 [46-49].

A possible effect of NPs on cellular gap junction crosstalk has been recently reported by Han and colleagues [50], although not in MSCs. Those authors demonstrated that iron oxide NPs significantly augmented the expression of $\mathrm{Cx} 43$ in $\mathrm{H} 9 \mathrm{C} 2$, which would be critical for gap junctional communication with MSCs in coculture for the generation of therapeutic potential-improved MSCs [50]. MSCs cocultured with iron oxide NP-harboring H9C2 cells showed active cellular crosstalk and displayed significantly higher levels of electrophysiological cardiac biomarkers and a cardiac repair-favorable paracrine profile, both of which are responsible for MI repair [50]. Our results, together with the above study, highlight an effect of NPs in developing gap junctional crosstalk among cells, extending the potential application of NPs in cell biology and stem cell-based therapies. Furthermore, this is a first study that shows an increase of $\mathrm{Cx} 43$ in hMSCs induced by $\mathrm{SiO}_{2}$-NPs internalization.

What might be the reason for the two observed biological effects in hMSCs? After internalization, $\mathrm{SiO}_{2}-\mathrm{NPs}$ readily accumulate in lysosomes, and this might transiently impact on the lysosomal function. Based on the results we obtained in this work, including the spontaneous normalization of the biological phenotypes by 8 days from $\mathrm{SiO}_{2}$-NP treatment, a time when normalization of lysosomal compartment could also be described, and the capability of reproducing the same biological effects by the use of a lysosomal activity inhibitor that impedes autophagosome-lysosome fusion, our conclusion is that accumulation of $\mathrm{SiO}_{2}-\mathrm{NPs}_{\text {in }}$ lysosomes cause a transient block of autophagic flux in hMSCs. In accordance, we found an accumulation of two autophagosome marker proteins, LC3-II and p62, in $\mathrm{SiO}_{2}-\mathrm{NP}$ treated cells and a near complete lack of colocalization between LC3 and $\mathrm{SiO}_{2}-\mathrm{NP}$-containing lysosomes. Accumulation of $\mathrm{SiO}_{2}-\mathrm{NPs}$ in lysosomes is thus predicted to result in transient inhibition of autophagy-mediated protein turnover in hMSCs, leading to perturbed degradation of cytosolic proteins, in perfect accordance with two recently published papers concerning lysosomal dysfunction caused by silica NPs [51,52]. Indeed, cell adhesion is one of the cellular processes described to be regulated by autophagy [53,54] 
and, early on in connexin research, it became clear that lysosomal pathways also contributed to the connexin degradation [55,56]; more recently, autophagy has emerged as a crucial connexin-degradation pathway for different connexin isoforms, including Cx-43 [57]. Notably, this transient dysfunction in lysosomal activity occurs in complete absence of any metabolic impairment or cytotoxicity in our cells, at variance with what has been reported for human cervix carcinoma cells [51] and human hepatocytes [52]. Lysosomal activity inhibition is subsequently overcome in hMSCs presumably due to $\mathrm{SiO}_{2}$-NP distribution to daughter cells and their consequent intracellular dilution [18], and the phenotypic effects released in parallel.

\section{Conclusion}

The data presented in this work suggest that $\mathrm{SiO}_{2}-\mathrm{NPs}$ should no longer be viewed as simple imaging agents for biomedical applications, but can also play an active role in mediating biological effects, some of which might ultimately result in an augmented stem cell engraftment potential. Considering, in particular, the modified microenvironment due to a myocardial infarction, which includes ischemia, inflammation and anoikis, where substrate adhesion and early intercellular communication abilities of the transplanted hMSCs are potentially the major contributors to cell engraftment and tissue regeneration, the observed positive $\mathrm{SiO}_{2}$-NP functional effects may represent a desirable biological improvement.

\section{Future Perspective}

Increased adhesion and engraftment of stem cells in the damaged myocardium as well as enhancement of functional gap junctions in stem cell plasma membrane due to interaction with lysosomal activity are interesting effects of NP internalization in human mesenchymal stem cells. NPs could represent a feasible tool to overcome some important limitations of stem cell-based therapies such as the low percentage of surviving and engrafted cells as well as the enhanced occurrence of arrhythmias in the injured cardiac tissue. Further study is needed to better understand whether NP internalization could influence also other aspects of stem cell behavior.

\section{Summary points}

- The therapeutic potential of human mesenchymal stem cells (hMSCs) in regenerating injured cardiac tissue is limited due to a low survival rate within the first week after transplantation.

- To enhance transplanted cell survival, adhesion capacity and interaction with the surrounding cells in the injured tissue should be improved.

- The aim of the present work was to evaluate whether any phenotypic effects could be exerted by internalization of silica nanoparticles $\left(\mathrm{SiO}_{2}\right.$-NPs) that might ultimately impact on the interaction of hMSCs with the cardiac environment.

Results

- $\mathrm{SiO}_{2}$-NP internalization impacted hMSC focal adhesion complexes, thus increasing in vitro adhesion capacity and engraftment in the myocardial tissue upon cell injection in infarcted isolated rat hearts.

- Furthermore, $\mathrm{SiO}_{2}$-NP treatment enhanced hMSC expression of Connexin-43, favoring hMSC interaction with cocultured cardiac myoblasts in an ischemia-like environment.

- $\mathrm{SiO}_{2}$-NPs affected lysosomal function by causing transient inhibition of autophagosome-lysosome fusion.

Conclusion

- Besides the use of NPs as simple imaging agents for biomedical applications, they should be considered for playing an active role in mediating biological effects, some of which might ultimately result in an augmented stem cell engraftment potential.

Supplementary data

To view the supplementary data that accompany this paper please visit the journal website at: www.futuremedicine.com/doi/sup $\mathrm{pl} / 10.2217 / \mathrm{nnm}-2017-0309$

Financial \& competing interests disclosure

This study was supported by GIAC_RILO_17_02 and PAGP_RILO_16_01. The authors have no other relevant affiliations or financial involvement with any organization or entity with a financial interest in or financial conflict with the subject matter or materials discussed in the manuscript apart from those disclosed.

No writing assistance was utilized in the production of this manuscript. 
Ethical conduct of research

This study conforms to the Guide for the Care and Use of Laboratory Animals published by the US National Institutes of Health (NIH Publication No. 85-23, revised 1996) and in compliance with the European Directive 2010/63/EU on the protection of animals used for scientific purposes. The local ethical committee approved the research project.

\section{Open access}

This work is licensed under the Attribution-NonCommercial-NoDerivatives 4.0 Unported License. To view a copy of this license, visit http://creativecommons.org/licenses/by-nc-nd/4.0/

\section{References}

Papers of special note have been highlighted as: $\bullet$ of interest; $\bullet \bullet$ of considerable interest

1. Rohban R, Pieber TR. Mesenchymal stem and progenitor cells in regeneration: tissue specificity and regenerative potential. Stem Cells Int. 2017, 5173732 (2017).

2. Gallina C, Turinetto V, Giachino C. A new paradigm in cardiac regeneration: the mesenchymal stem cell secretome. Stem Cells Int. 2015, 765846 (2015).

3. Singh A, Singh A, Sen D. Mesenchymal stem cells in cardiac regeneration: a detailed progress report of the last 6 years (2010-2015). Stem Cell Res. Ther. 7(1), 82 (2016).

4. Lee S, Choi E, Cha M-J, Hwang K-C. Cell adhesion and long-term survival of transplanted mesenchymal stem cells: a prerequisite for cell therapy. Oxid. Med. Cell. Longev. 2015, 632902 (2015).

5. Taddei ML, Giannoni E, Fiaschi T, Chiarugi P. Anoikis: an emerging hallmark in health and diseases. J. Pathol. 226(2), 380-393 (2012).

6. Michel J-B. Anoikis in the cardiovascular system: known and unknown extracellular mediators. Arterioscler. Thromb. Vasc. Biol. 23(12), 2146-2154 (2003).

7. Kavanagh DPJ, Robinson J, Kalia N. Mesenchymal stem cell priming: fine-tuning adhesion and function. Stem Cell Rev. 10(4), 587-599 (2014).

8. den Haan MC, van Zuylen V-L, Pluijmert NJ et al. Discrepant results of experimental human mesenchymal stromal cell therapy after myocardial infarction: are animal models robust enough? PLoS ONE 11(4), e0152938 (2016).

9. Gnecchi M, Zhang Z, Ni A, Dzau VJ. Paracrine mechanisms in adult stem cell signaling and therapy. Circ. Res. 103(11), 1204-1219 (2008).

10. Liu C, Fan Y, Zhou L et al. Pretreatment of mesenchymal stem cells with angiotensin II enhances paracrine effects, angiogenesis, gap junction formation and therapeutic efficacy for myocardial infarction. Int. J. Cardiol. 188, 22-32 (2015).

11. Valiunas V, Doronin S, Valiuniene L et al. Human mesenchymal stem cells make cardiac connexins and form functional gap junctions. J. Physiol. 555(Pt 3), 617-626 (2004).

12. Patel S, Lee K-B. Probing stem cell behavior using nanoparticle-based approaches. Wiley Interdiscip. Rev. Nanomed. Nanobiotechnol. 7(6), 759-778 (2015).

13. Accomasso L, Gallina C, Turinetto V, Giachino C. Stem cell tracking with nanoparticles for regenerative medicine purposes: an overview. Stem Cells Int. 2016 , 7920358 (2016).

14. Liao L. Nanoparticle-dependent labeling of mesenchymal stem cell. J. Nanosci. Nanotechnol. 14(1), 958-968 (2014).

15. Bokara KK, Oggu GS, Vidyasagar AJ, Asthana A, Lee JE, Rao CM. Modulation of stem cell differentiation by the influence of nanobiomaterials/carriers. Curr. Stem Cell Res. Ther. 9(6), 458-468 (2014).

16. Accomasso L, Cibrario Rocchietti E, Raimondo $S$ et al. Fluorescent silica nanoparticles improve optical imaging of stem cells allowing direct discrimination between live and early-stage apoptotic cells. Small 8(20), 3192-200 (2012).

17. Catalano F, Accomasso L, Alberto G et al. Factors ruling the uptake of silica nanoparticles by mesenchymal stem cells: agglomeration versus dispersions, absence versus presence of serum proteins. Small 11(24), 2919-2928 (2015).

18. Gallina C, Capeloa T, Saviozzi $S$ et al. Human mesenchymal stem cells labelled with dye-loaded amorphous silica nanoparticles: long-term biosafety, stemness preservation and traceability in the beating heart. J. Nanobiotechnol. 13, 77 (2015).

-• Demonstrates biosafety of silica-nanoparticles we use and optimizes protocol for labeling human mesenchymal stem cells.

19. Alberto G, Miletto I, Viscardi G et al. Hybrid cyanine-silica nanoparticles: homogeneous photoemission behavior of entrapped fluorophores and consequent high brightness enhancement. J. Phys. Chem. C. 113(50), 21048-21053 (2009).

20. Miletto I, Gilardino A, Zamburlin P et al. Highly bright and photostable cyanine dye-doped silica nanoparticles for optical imaging: photophysical characterization and cell tests. Dye Pigment 84(1), 121-127 (2010).

21. Raimondo S, Penna C, Pagliaro P, Geuna S. Morphological characterization of GFP stably transfected adult mesenchymal bone marrow stem cells. J. Anat. 208(1), 3-12 (2006).

22. Schneider CA, Rasband WS, Eliceiri KW. NIH Image to ImageJ: 25 years of image analysis. Nat. Methods 9(7), 671-675 (2012). 
23. Penna C, Raimondo S, Ronchi G et al. Early homing of adult mesenchymal stem cells in normal and infarcted isolated beating hearts. $J$. Cell. Mol. Med. 12(2), 507-521 (2008).

24. Ziambaras K, Lecanda F, Steinberg TH, Civitelli R. Cyclic stretch enhances gap junctional communication between osteoblastic cells. J. Bone Miner. Res. 13(2), 218-228 (1998).

25. Cselenyák A, Pankotai E, Horváth EM et al. Mesenchymal stem cells rescue cardiomyoblasts from cell death in an in vitro ischemia model via direct cell-to-cell connections. BMC Cell Biol. 11(1), 29 (2010).

26. Parsons JT, Horwitz AR, Schwartz MA. Cell adhesion: integrating cytoskeletal dynamics and cellular tension. Nat. Rev. Mol. Cell Biol. 11(9), 633-643 (2010).

27. Ridley AJ. Life at the leading edge. Cell 145(7), 1012-1022 (2011).

28. Webb DJ, Parsons JT, Horwitz AF. Adhesion assembly, disassembly and turnover in migrating cells - over and over and over again. Nat. Cell Biol. 4(4), E97-E100 (2002).

29. Humphries JD, Wang P, Streuli C, Geiger B, Humphries MJ, Ballestrem C. Vinculin controls focal adhesion formation by direct interactions with talin and actin. J. Cell Biol. 179(5), 1043-1057 (2007).

30. Wang C, Gong Y, Zhong Y, Yao Y, Su K, Wang D-A. The control of anchorage-dependent cell behavior within a hydrogel/microcarrier system in an osteogenic model. Biomaterials 30(12), 2259-2269 (2009).

31. Besser A, Safran SA. Force-induced adsorption and anisotropic growth of focal adhesions. Biophys. J. 90(10), 3469-3484 (2006).

32. Wolfenson H, Henis YI, Geiger B et al. Theheel and toe of the cell's foot: a multifaceted approach for understanding thestructure and dynamics of focal adhesions. Cell Motil. Cytoskeleton 66(11), 1017-1029 (2009).

33. Valiente-Alandi I, Schafer AE, Blaxall BC. Extracellular matrix-mediated cellular communication in the heart. J. Mol. Cell. Cardiol. 91 , 228-237 (2016).

34. Tay CY, Cai P, Setyawati MI et al. Nanoparticles strengthen intracellular tension and retard cellular migration. Nano Lett. 14(1), 83-88 (2014).

35. Hou Y, Cai K, Li J et al. Effects of titanium nanoparticles on adhesion, migration, proliferation, and differentiation of mesenchymal stem cells. Int. J. Nanomedicine 8, 3619-3630 (2013).

36. Hackenberg S, Scherzed A, Technau A, Froelich K, Hagen R, Kleinsasser N. Functional responses of human adipose tissue-derived mesenchymal stem cells to metal oxide nanoparticles in vitro. J. Biomed. Nanotechnol. 9(1), 86-95 (2013).

37. Akimov SS, Krylov D, Fleischman LF, Belkin AM. Tissue transglutaminase is an integrin-binding adhesion coreceptor for fibronectin. J. Cell Biol. 148(4), 825-838 (2000).

38. Song H, Chang W, Lim S et al. Tissue transglutaminase is essential for integrin-mediated survival of bone marrow-derived mesenchymal stem cells. Stem Cells 25(6), 1431-1438 (2007).

39. Benoit DSW, Tripodi MC, Blanchette JO, Langer SJ, Leinwand LA, Anseth KS. Integrin-linked kinase production prevents anoikis in human mesenchymal stem cells. J. Biomed. Mater. Res. A 81(2), 259-268 (2007).

40. Song S-W, Chang W, Song B-W et al. Integrin-linked kinase is required in hypoxic mesenchymal stem cells for strengthening cell adhesion to ischemic myocardium. Stem Cells 27(6), 1358-1365 (2009).

41. Chang W, Song BW, Hwang KC. Mesenchymal stem cell survival in infarctedmyocardium: adhesion and anti-death signals. In: Stem Cells and Cancer Stem Cells, Volume 10: Therapeutic Applications in Disease andInjury. Hayat MA (Ed.). Springer, Dordrecht, the Netherlands, 35-43 (2013).

42. Sato D, Xie L-H, Sovari AA et al. Synchronization of chaotic early afterdepolarizations in the genesis of cardiac arrhythmias. Proc. Natl Acad. Sci. USA 106(9), 2983-2988 (2009).

43. de Bakker JM, van Capelle FJ, Janse MJ et al. Slow conduction in the infarcted human heart. "Zigzag" course of activation. Circulation 88(3), 915-926 (1993).

44. Beeres SLMA, Zeppenfeld K, Bax JJ et al. Electrophysiological and arrhythmogenic effects of intramyocardial bone marrow cell injection in patients with chronic ischemic heart disease. Heart Rhythm 4(3), 257-265 (2007).

45. Chen H-SV, Kim C, Mercola M. Electrophysiological challenges of cell-based myocardial repair. Circulation 120(24), 2496-2508 (2009).

46. Roell W, Lewalter T, Sasse P et al. Engraftment of connexin 43-expressing cells prevents post-infarct arrhythmia. Nature 450(7171), 819-824 (2007).

47. Hahn J-Y, Cho H-J, Kang H-J et al. Pre-treatment of mesenchymal stem cells with a combination of growth factors enhances gap junction formation, cytoprotective effect on cardiomyocytes, and therapeutic efficacy for myocardial infarction. J. Am. Coll. Cardiol. 51(9), 933-943 (2008).

48. Song $\mathrm{H}, \mathrm{Hwang} \mathrm{HJ}$, Chang $\mathrm{W}$ et al. Cardiomyocytes from phorbol myristate acetate-activated mesenchymal stem cells restore electromechanical function in infarcted rat hearts. Proc. Natl Acad. Sci. USA 108(1), 296-301 (2011).

49. Carvalho JL, Braga VBA, Melo MB et al. Priming mesenchymal stem cells boosts stem cell therapy to treat myocardial infarction. J. Cell. Mol. Med. 17(5), 617-625 (2013). 
50. Han J, Kim B, Shin J-Y et al. Iron oxide nanoparticle-mediated development of cellular gap junction crosstalk to improve mesenchymal stem cells' therapeutic efficacy for myocardial infarction. ACS Nano 9(3), 2805-2819 (2015).

51. Schütz I, Lopez-Hernandez T, Gao Q et al. Lysosomal dysfunction caused by cellular accumulation of silica nanoparticles. J. Biol. Chem. 291(27), 14170-14184 (2016).

- Highlights a role of silica-nanoparticles in cell proteins turnover.

52. Wang J, Yu Y, Lu K et al. Silica nanoparticles induce autophagy dysfunction via lysosomal impairment and inhibition of autophagosome degradation in hepatocytes. Int. J. Nanomed. 12, 809-825 (2017).

53. Ballabio A. The awesome lysosome. EMBO Mol. Med. 8(2), 73-76 (2016).

54. Pu J, Guardia CM, Keren-Kaplan T, Bonifacino JS. Mechanisms and functions of lysosome positioning. J. Cell Sci. 129(23), 4329-4339 (2016).

55. Laing JG, Beyer EC. The gap junction protein connexin 43 is degraded via the ubiquitin proteasome pathway. J. Biol. Chem. 270(44), 26399-26403 (1995).

56. Laing JG, Tadros PN, Westphale EM, Beyer EC. Degradation of connexin 43 gap junctions involves both the proteasome and the lysosome. Exp. Cell Res. 236(2), 482-492 (1997).

57. Iyyathurai J, Decuypere J-P, Leybaert L, D’hondt C, Bultynck G. Connexins: substrates and regulators of autophagy. BMC Cell Biol. 17(Suppl. 1), 20 (2016). 